\title{
Parameter Extraction of Solar Photovoltaic Modules Using Gravitational Search Algorithm
}

\author{
R. Sarjila, K. Ravi, J. Belwin Edward, K. Sathish Kumar, and Avagaddi Prasad \\ School of Electrical Engineering, VIT University, Vellore, Tamil Nadu, India \\ Correspondence should be addressed to R. Sarjila; r.sarjila@yahoo.com
}

Received 28 July 2016; Revised 4 November 2016; Accepted 22 November 2016

Academic Editor: Ahmed M. Soliman

Copyright (C) 2016 R. Sarjila et al. This is an open access article distributed under the Creative Commons Attribution License, which permits unrestricted use, distribution, and reproduction in any medium, provided the original work is properly cited.

\begin{abstract}
Parameter extraction of a solar photovoltaic system is a nonlinear problem. Many optimization algorithms are implemented for this purpose, which failed in giving better results at low irradiance levels. This article presents a novel method for parameter extraction using gravitational search algorithm. The proposed method evaluates the parameters of different PV panels at various irradiance levels. A critical evaluation and comparison of gravitational search algorithm with other optimization techniques such as genetic algorithm are given. Extensive simulation analyses are carried out on the proposed method and show that GSA is much suitable for parameter extraction problem.
\end{abstract}

\section{Introduction}

Precise parameters extraction of solar photovoltaic cells is normally a vital part of a solar photovoltaic (PV) system, which can be interfaced with maximum power point tracker (MPPT) calculations and power electronic converters. This undertaking is vital for the device modelling, characterization, and simulation and for the device quality testing. Maximum power point tracker, ordinarily alluded to as MPPT, is an electronic framework that works the PV modules in a way that permits the modules to deliver all the force they are able to do [1]. MPPT is not a mechanical following framework that "physically moves" the modules to make them point all the more straightforwardly at the sun. MPPT is a completely electronic framework which highlights a brilliant attaching calculation that changes the electrical working purpose of the modules so that the modules can convey most extreme accessible force. Extra power collected from the modules is then made accessible as expanded battery charge current. MPPT calculations are essential in PV applications in light of the fact that the maximum power point (MPP) of a sun oriented board changes with the illumination and temperature, so the utilization of MPPT calculations [2] is required keeping in mind the end goal to acquire the most extreme force from a sun based exhibit. The present scope technique utilizes a range waveform for the PV cluster current such that the $I-V$ normal for the PV exhibit is gotten and upgraded at settled time interims. The most extreme force point voltage can then be processed from the trademark bend at the same interims.

The above addressed problem can be solved efficiently by many prominent techniques. But each prominent technique $[3,4]$ has its own advantages and limitations. Some of the common drawbacks are neglecting the effects of high level injection and the assumption that the diode was operating in low-level injection while deriving the Shockley equation. These drawbacks can be overcome using the proposed GSA method. In this aspect GSA is found to be superior to other techniques. In parameter extraction, the parameters of the solar panel other than the data given in the manufacturer's data sheet are optimized using an optimization technique. It is done such that the power delivered from the solar panel is maximum even though the solar irradiation and temperature change. These values are then fed into a SIMULINK model which gives the VI characteristics of the panel. Output of the SIMULINK model is then compared with the data sheet characteristics. The error has to be less.

\section{Gravitational Search Algorithm}

In the recent past, different heuristic advancement techniques have been created. Huge numbers of these strategies are 


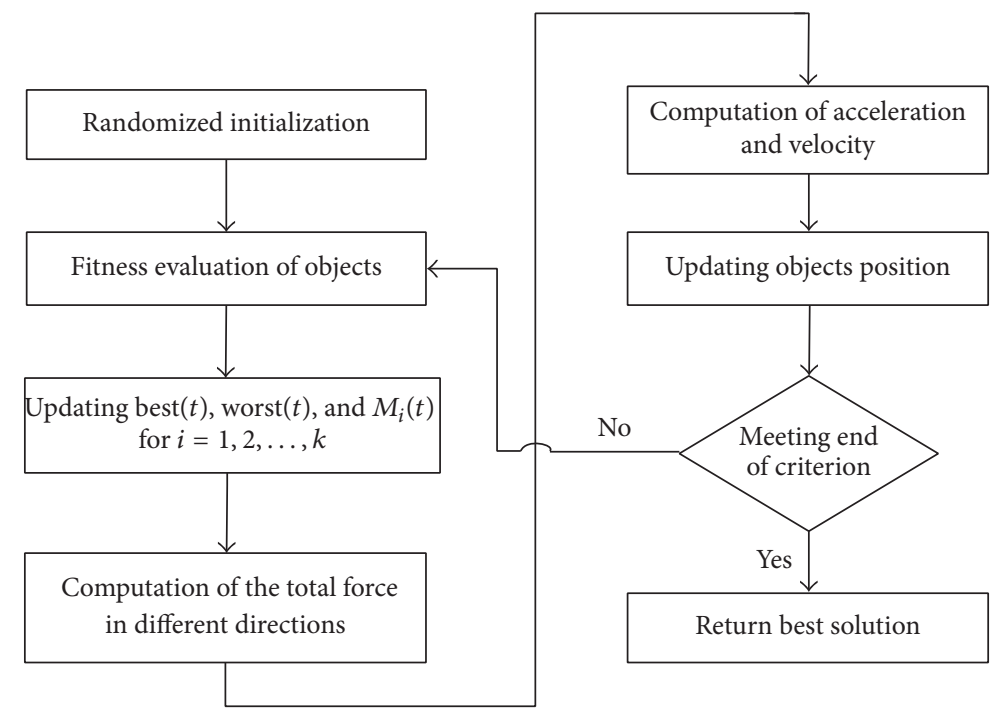

FIGURE 1: Flowchart of gravitational search algorithm.

propelled by swarm practices in nature. In this paper, another advancement calculation in light of the law of gravity and mass connections is presented [5]. There are a few points of interest of GSA that demonstrate its centrality contrasted and other nature enlivened systems. To start with, it requires just two parameters to modify, that is, mass and velocity of particles, and second is has capacity to discover close global optimum solution. The capacity to discover close global optimum solution makes the GSA vary from other nature inspired algorithms. In the proposed calculation, the searcher specialists are an accumulation of masses which connect with each other in light of the Newtonian gravity and the laws of movement. The proposed technique has been contrasted and some understood heuristic pursuit strategies [6]. The acquired results affirm the superiority of the proposed technique in illuminating different nonlinear capacities. Figure 1 shows the flowchart of gravitational search algorithm.

\subsection{Algorithm for GSA}

Step 1 (initialization).

Current position: position of particles

Velocity: velocity

Force: the gravitational force between the particles

Acceleration: acceleration

Mass: mass

Dim: dimension of test functions

$N$ : number of particles

$G_{o}$ : gravitational constant

Low, up: search space limits

Step 2. Read the parameters of the PV panel under consideration.
Step 3 (search space identification). Agents that go out of the search space are returned to the boundaries.

Step 4 (evaluation of the population). The objective function is calculated for each iteration.

Step 5 (mass calculation). Mass of each agent is calculated.

$$
\text { Loop: } i=1: n \text {. }
$$

Step 6 (force update). Force is updated for each mass.

$$
\text { Loop: } k=1: n
$$

Step 7. Update acceleration and velocity.

$$
\text { Loop: } i=1: n
$$

Step 8. Update agent's position.

Step 9. Repeat Step 4 until the stop criterion is reached.

Step 10. Print the result.

\section{Modelling of Photovoltaic Panel}

The single diode condition accepts a steady esteem for the ideality factor $n$. In all actuality the ideality factor is a function of voltage over the device. At high voltage, when the recombination in the device is overwhelmed by the surfaces and the huge regions the ideality factor is near one. However, at lower voltages, recombination in the intersection is overwhelmed and the ideality factor approaches two. The intersection recombination is displayed by including a second diode in parallel with the first and setting the ideality consideration regularly to two. The equivalent circuit for double diode model is shown in Figure 2. 


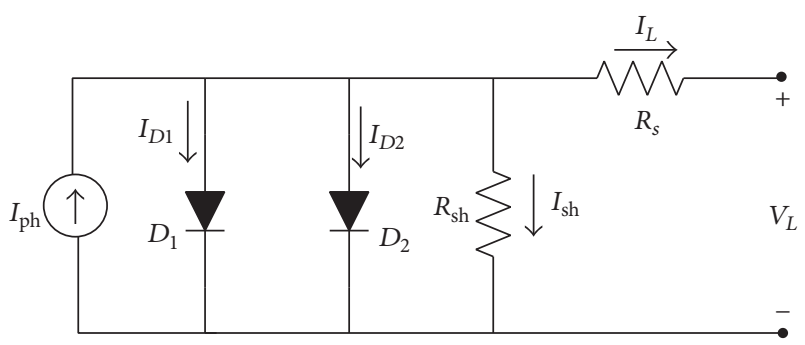

FIGURE 2: Double diode model of solar cell.

In this double diode model, the cell terminal current is calculated as follows:

$$
I_{L}=I_{\mathrm{ph}}-I_{D 1}-I_{D 2}-I_{\mathrm{sh}}
$$

where $I_{L}$ is terminal current, $I_{\mathrm{ph}}$ is cell-generated photocurrent, $I_{D 1}, I_{D 2}$ are first and second diode currents, and $I_{\mathrm{sh}}$ is shunt resistor current.

The diode current equations and leakage current equation are given by

$$
\begin{aligned}
& I_{D 1}=I_{01}\left[\exp \left(\frac{q\left(V_{L}+I R_{s}\right)}{a_{1} k T}\right)-1\right] \\
& I_{D 2}=I_{02}\left[\exp \left(\frac{q\left(V_{L}+I R_{s}\right)}{a_{2} k T}\right)-1\right] \\
& I_{\mathrm{sh}}=\frac{V_{L}+I R_{s}}{R_{\mathrm{sh}}}
\end{aligned}
$$

where $R_{s}$ and $R_{\mathrm{sh}}$ are the series and shunt resistances, respectively; $V_{L}$ is the terminal voltage; $a_{1}, a_{2}$ are the diffusion and recombination diode ideality factors; $k$ is Boltzmann's constant; $q$ is the electronic charge; and $T$ is the cell absolute temperature in Kelvin.

Thus the expression for cell terminal current is formulated as

$$
\begin{aligned}
I_{L}= & I_{\mathrm{ph}}-I_{01}\left[\exp \left(\frac{q\left(V_{L}+I R_{s}\right)}{a_{1} k T}\right)-1\right] \\
& -I_{02}\left[\exp \left(\frac{q\left(V_{L}+I R_{s}\right)}{a_{2} k T}\right)-1\right]-\frac{V_{L}+I R_{s}}{R_{\mathrm{sh}}} .
\end{aligned}
$$

$$
\begin{aligned}
& J=\left|\frac{d I_{L}}{d V_{L}}\right|_{\left(V_{\mathrm{mp}}, I_{\mathrm{mp}}\right)}+\frac{I_{\mathrm{mp}}}{V_{\mathrm{mp}}} \\
& \left|\frac{d I_{L}}{d V_{L}}\right|
\end{aligned}
$$

$$
=\frac{\left(I_{01} \times L_{1} \times \exp \left(L_{1} \times\left(V_{\mathrm{mpp}}+\left(I_{\mathrm{mpp}} \times R_{s}\right)\right)\right)+I_{02} \times L_{2} \times \exp \left(L_{2} \times\left(V_{\mathrm{mpp}}+\left(I_{\mathrm{mpp}} \times R_{s}\right)\right)\right)+G_{p}\right)}{\left(1+I_{01} \times L_{1} \times R_{s} \times \exp \left(L_{1} \times\left(V_{\mathrm{mpp}}+\left(I_{\mathrm{mpp}} \times R_{s}\right)\right)\right)+I_{02} \times L_{2} \times R_{s} \times \exp \left(L_{2} \times\left(V_{\mathrm{mpp}}+\left(I_{\mathrm{mpp}} \times R_{s}\right)\right)\right)+\left(G_{p} \times R_{s}\right)\right)+\left(I_{\mathrm{mpp}} / V_{\mathrm{mpp}}\right)},
$$

where $L_{1}=1 / a_{1} V_{t} ; L_{2}=1 / a_{2} V_{t} ; V_{\mathrm{mpp}}$ is Peak Power Voltage; $I_{\mathrm{mpp}}$ is Peak Power Current; $G_{p}=1 / R_{p}$.
The seven parameters to be estimated that fully describe the $I$ - $V$ characteristics are $R_{s}, R_{\mathrm{sh}}, I_{\mathrm{ph}}, I_{01}, I_{02}, a_{1}$, and $a_{2}$.

3.1. Problem Formulation. The parameters $R_{s}, R_{\mathrm{sh}}, I_{\mathrm{ph}}, I_{01}$, $I_{02}, a_{1}$, and $a_{2}$ with temperature and irradiance depend on manufacturing tolerance. Such functions have no explicit analytical solutions for either $I_{L}$ or $V_{L}$. The GSA optimization technique [6] is employed to estimate the parameters by minimizing a preselected objective function which is given by

$$
f\left(V_{L}, I_{L}, I_{\mathrm{ph}}, I_{01}, I_{02}, R_{s}, R_{\mathrm{sh}}, a_{1}, a_{2}\right)=0 .
$$

The new objective function that sums the individual absolute errors (IAEs) for any given set of measurements is defined as

$$
f=\sum_{i=1}^{N}\left|f\left(V_{i}, I_{i}, I_{01}, I_{02}, R_{s}, R_{\mathrm{sh}}, a_{1}, a_{2}\right)\right|
$$

where $N$ is the number of data points and $I_{i}$ and $V_{i}$ are $i$ th measured current and voltage pair values, respectively.

Objective Function. At maximum power point, the derivative of the power with respect to voltage is equal to zero. That is,

$$
\frac{d P}{d V_{L}}=0
$$

The power equation is written as $P=V I_{L}$. Applying condition for MPP the above equation changes to

$$
\frac{d P}{d V_{L}}=\left[V_{L} \times\left(\frac{d I_{L}}{d V_{L}}\right)\right]+I_{L} .
$$

In order to obtain the maximum power the term $d P / d V_{L}$ has to be made zero.

So, RHS is equated to zero.

$$
\begin{aligned}
{\left[V_{L} \times\left(\frac{d I_{L}}{d V_{L}}\right)\right]+I_{L} } & =0 . \\
\left(\frac{d I_{L}}{d V_{L}}\right)+\left(\frac{I_{L}}{V_{L}}\right) & =0 .
\end{aligned}
$$

The objective function to be minimized is 


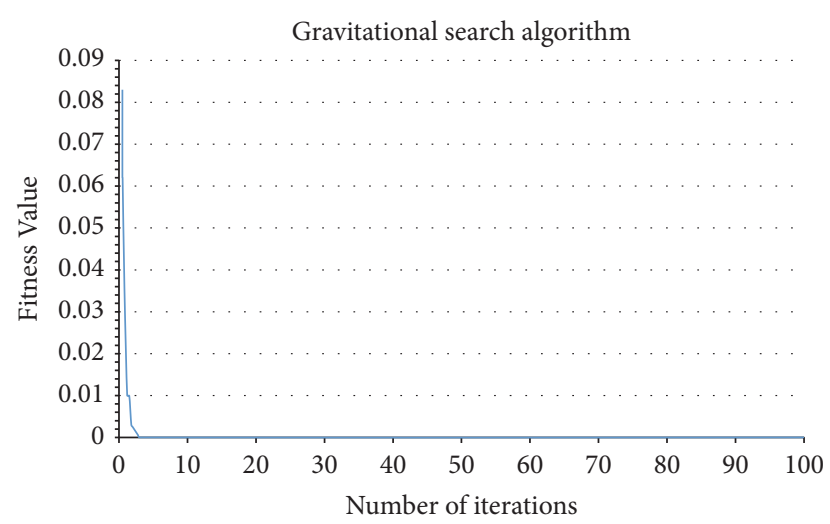

FIgURE 3: Convergence graph for Shell S36.

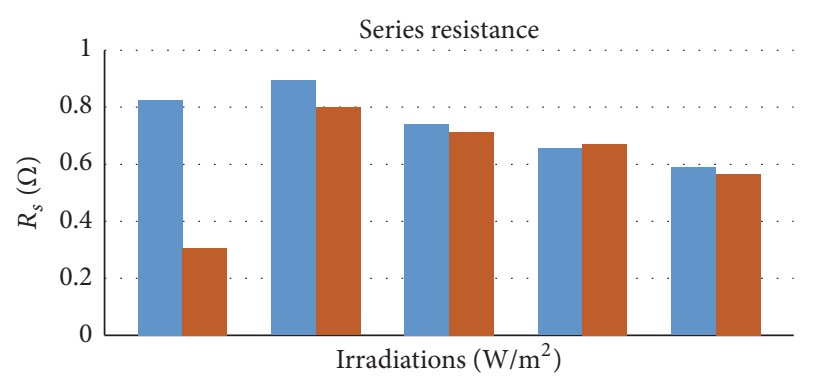

GA

GSA

Figure 4: Comparison of the optimized series resistance values of Shell S36 under different irradiance conditions.

characteristics of solar PV modules. Three different panels are considered in this work to validate the efficiency of the proposed method; they are monocrystalline (Shell SP70), thin film (Shell ST40), and multicrystalline (Shell S36). The simulated parameters are compared with the manufacturer's data [7-9].

\section{Results and Discussions}

Parameter extraction is performed for the 3 above mentioned solar panels. The optimal values of the parameters for respective panels are found out such that the variation of power with respect to voltage is minimum so that the overall power output is maximum. The convergence curves for shells S36 at standard temperature condition of $1000 \mathrm{~W} / \mathrm{m}^{2}$ irradiation and temperature of $25^{\circ} \mathrm{C}$ are shown in Figure 3.

Comparison of the optimized series resistance, shunt resistance, and ideality factor values of Shell S36 under different irradiance conditions is shown in Figures 4, 5, and 6 , respectively.

The simulated characteristics curves of the SIMULINK model for Shell S36 at different irradiations are shown in Figure 7.

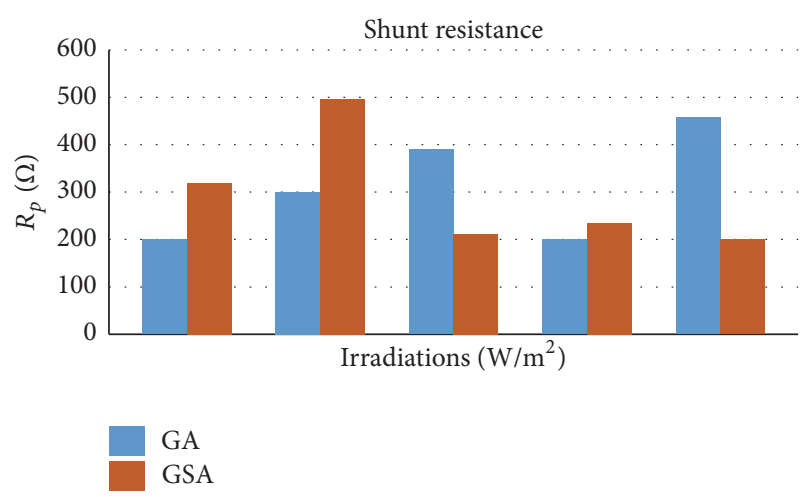

FIGURE 5: Comparison of the optimized shunt resistance values of Shell S36 under different irradiance conditions.

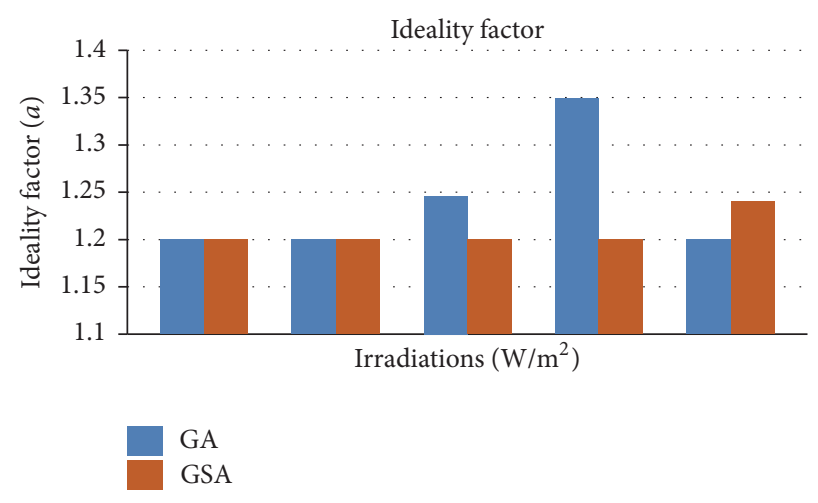

FIgURE 6: Comparison of the optimized ideality factor values of Shell S36 under different irradiance conditions.

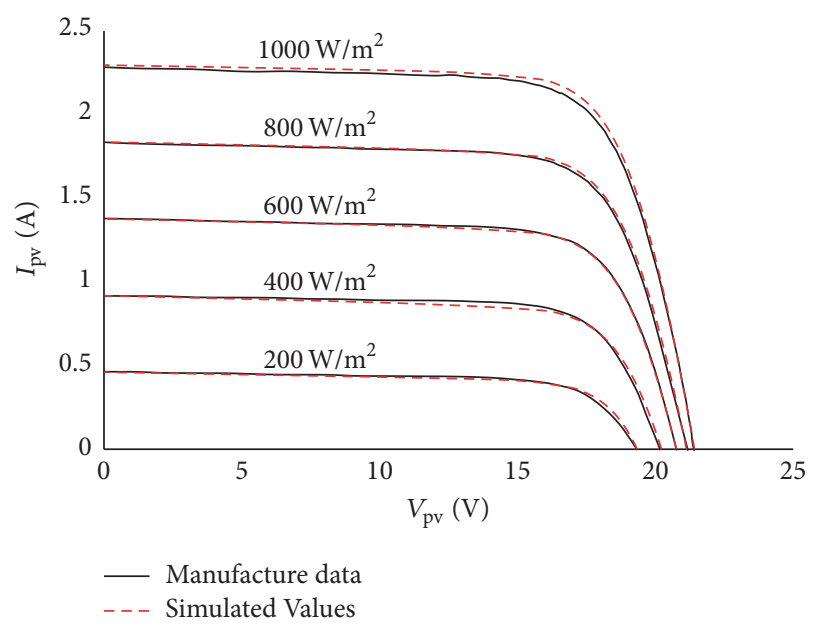

FIGURE 7: $I_{\mathrm{pv}}-V_{\mathrm{pv}}$ characteristic curves at different irradiation levels for Shell S36.

4.1. Comparison of GA and GSA for Different Irradiations. Optimization results of the algorithms GA and GSA at different irradiation levels for Shell S36, Shell ST40, and Shell SP70 are compared and tabulated in Tables 1, 2, and 3, respectively. 
TABLE 1: Comparison of optimization results of GA and GSA at different irradiation levels for Shell S36.

\begin{tabular}{|c|c|c|c|c|c|c|c|c|c|c|}
\hline \multirow{3}{*}{ Parameters } & \multicolumn{10}{|c|}{ Irradiation in Watt $/ \mathrm{m}^{2}$} \\
\hline & \multicolumn{2}{|c|}{200} & \multicolumn{2}{|c|}{400} & \multicolumn{2}{|c|}{600} & \multicolumn{2}{|c|}{800} & \multicolumn{2}{|c|}{1000} \\
\hline & GA & GSA & GA & GSA & GA & GSA & GA & GSA & GA & GSA \\
\hline$R_{s}(\Omega)$ & 0.825024 & 0.3069 & 0.8935 & 0.7996 & 0.7429 & 0.717498 & 0.656891 & 0.660802 & 0.59042 & 0.59824 \\
\hline$R_{p}(\Omega)$ & 200 & 319.6481 & 300.098 & 496.5787 & 390.029 & 212.121 & 200 & 234.6041 & 457.478 & 200 \\
\hline$a_{1}$ & 1.2 & 1.2 & 1.2 & 1.2 & 1.246 & 1.2 & 1.3489 & 1.2 & 1.2 & 1.24 \\
\hline$a_{2}$ & 1 & 1 & 1 & 1 & 1 & 1 & 1 & 1 & 1 & 1 \\
\hline$I_{01}(\mathrm{nA})$ & 56.4 & 56.4 & 5.23 & 5.23 & 10.3 & 10.2 & 43.0 & 4.85 & 4.73 & 4.73 \\
\hline$I_{02}(\mathrm{nA})$ & 0.147 & 0.147 & 0.117 & 0.117 & 0.21 & 0.21 & 0.0933 & 0.0933 & 0.0867 & 0.0867 \\
\hline$I_{\mathrm{pv}}(\mathrm{A})$ & 0.46 & 0.46 & 0.92 & 0.92 & 1.38 & 1.38 & 1.84 & 1.84 & 2.3 & 2.3 \\
\hline
\end{tabular}

TABLE 2: Comparison of optimization results of GA and GSA at different irradiation levels for Shell ST40.

\begin{tabular}{|c|c|c|c|c|c|c|c|c|c|c|}
\hline \multirow{3}{*}{ Parameters } & \multicolumn{10}{|c|}{ Irradiation in Watt $/ \mathrm{m}^{2}$} \\
\hline & \multicolumn{2}{|c|}{200} & \multicolumn{2}{|c|}{400} & \multicolumn{2}{|c|}{600} & \multicolumn{2}{|c|}{800} & \multicolumn{2}{|c|}{1000} \\
\hline & GA & GSA & GA & GSA & GA & GSA & GA & GSA & GA & GSA \\
\hline$R_{s}(\Omega)$ & 0.957967 & 0.940371 & 0.995112 & 0.983382 & 0.995112 & 0.995112 & 0.981427 & 0.981427 & 0.991202 & 0.999 \\
\hline$R_{p}(\Omega)$ & 480.9384 & 200 & 291.3001 & 200 & 295.2102 & 200 & 420.3324 & 200 & 333.33 & 200 \\
\hline$a_{1}$ & 1.480938 & 1.492669 & 1.2 & 1.404692 & 1.2 & 1.4604 & 1.2317 & 1.486804 & 1.2 & 1.4956 \\
\hline$a_{2}$ & 1 & 1 & 1 & 1 & 1 & 1 & 1 & 1 & 1 & 1 \\
\hline$I_{01}(\mathrm{nA})$ & 52.0 & 57.2 & 1.10 & 22.4 & 1.05 & 1.05 & 1.77 & 68.6 & 0.996 & 72.8 \\
\hline$I_{02}(\mathrm{nA})$ & 0.022 & 0.022 & 0.0175 & 0.0175 & 0.0153 & 0.0153 & 0.0139 & 0.0134 & 0.0129 & 0.0129 \\
\hline$I_{\mathrm{pv}}(\mathrm{A})$ & 0.536 & 0.536 & 1.072 & 1.072 & 1.608 & 1.608 & 2.144 & 2.144 & 2.68 & 2.68 \\
\hline
\end{tabular}

TABLE 3: Comparison of optimization results of GA and GSA at different irradiation levels for Shell SP70.

\begin{tabular}{|c|c|c|c|c|c|c|c|c|c|c|}
\hline \multirow{3}{*}{ Parameters } & \multicolumn{10}{|c|}{ Irradiation in Watt $/ \mathrm{m}^{2}$} \\
\hline & \multicolumn{2}{|c|}{200} & \multicolumn{2}{|c|}{400} & \multicolumn{2}{|c|}{600} & \multicolumn{2}{|c|}{800} & \multicolumn{2}{|c|}{1000} \\
\hline & GA & GSA & GA & GSA & GA & GSA & GA & GSA & GA & GSA \\
\hline$R_{s}(\Omega)$ & 0.01173 & 0.066471 & 0.197458 & 0.02346 & 0.250244 & 0.113392 & 0.26002 & 0.183773 & 0.26002 & 0.144673 \\
\hline$R_{p}(\Omega)$ & 255.132 & 499.5112 & 285.435 & 470.1857 & 260.016 & 487.781 & 200 & 237.5367 & 424.2424 & 385.1417 \\
\hline$a_{1}$ & 1.322 & 1.2 & 1.2 & 1.2 & 1.2 & 1.2 & 1.2 & 1.2 & 1.2 & 1.293255 \\
\hline$a_{2}$ & 1 & 1 & 1 & 1 & 1 & 1 & 1 & 1 & 1 & 1 \\
\hline$I_{01}(\mathrm{nA})$ & 11.5 & 11.5 & 10.7 & 10.7 & 10.2 & 10.2 & 9.91 & 9.91 & 9.67 & 9.67 \\
\hline$I_{02}(\mathrm{nA})$ & 0.301 & 0.301 & 0.24 & 0.24 & 0.21 & 0.21 & 0.191 & 0.191 & 0.177 & 0.177 \\
\hline$I_{\mathrm{pv}}(\mathrm{A})$ & 0.94 & 0.94 & 1.88 & 1.88 & 2.82 & 2.82 & 3.76 & 3.76 & 4.7 & 4.7 \\
\hline
\end{tabular}

4.2. Estimation of Absolute Error. To predict the closeness of the results obtained, absolute error is estimated for the proposed and GA method. Absolute error is computed using the following equation:

$$
\text { Absolute error }=I_{\text {experimental }}-I_{\text {computed }} \text {. }
$$

The computed absolute error graph for Shell S36 is presented in Figure 8. To maintain higher level of accuracy and clarity, the results are compared at the same points.

\section{Conclusion}

In this work, the parameters of the PV module are determined using the proposed GSA. The simulated voltage-current characteristics for three different panels (Shell S36, Shell SP70, and Shell ST40), obtained from the simulation model, are validated with the extracted experimental data. Further, the absolute error curve is plotted for GSA in comparison with GA at different irradiance level $\left(200\right.$ to $\left.1000 \mathrm{~W} / \mathrm{m}^{2}\right)$ at $25^{\circ} \mathrm{C}$. It is observed that the error obtained in case of GSA is lesser. The extensive simulation results show that the proposed GSA method is superior to the existing GA in terms 


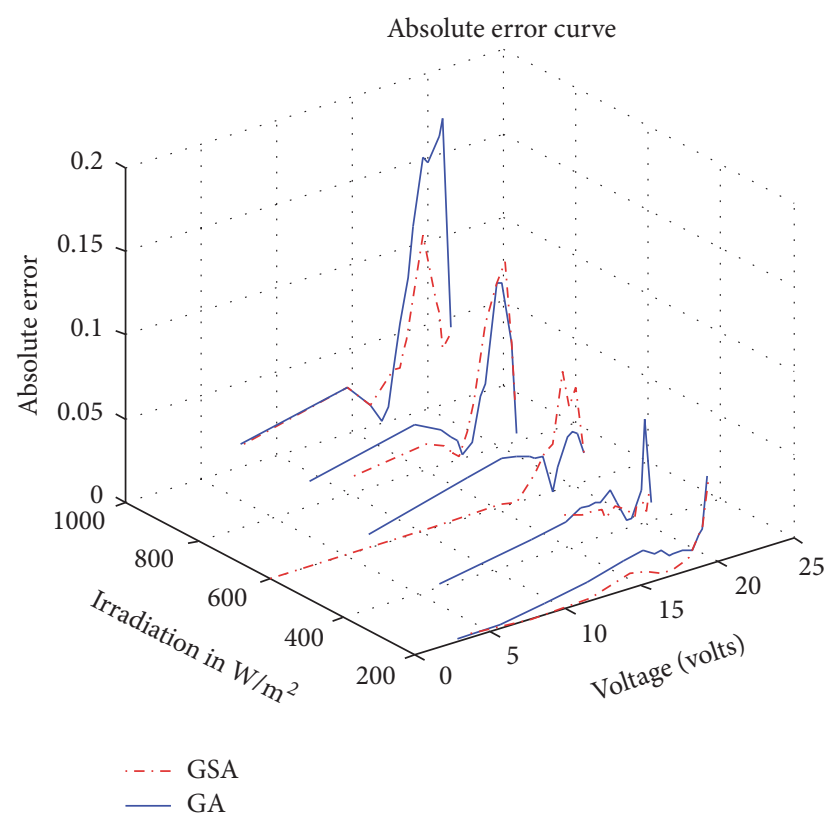

FIGURE 8: Error graph for Shell S36.

of speed of convergence, accuracy, computational efficiency, and consistency of solution.

\section{Competing Interests}

The authors declare that there are no competing interests regarding the publication of this paper.

\section{References}

[1] D. Verma, S. Nema, A. M. Shandilya, and S. K. Dash, "Maximum power point tracking (MPPT) techniques: recapitulation in solar photovoltaic systems," Renewable and Sustainable Energy Reviews, vol. 54, pp. 1018-1034, 2016.

[2] B. Bendib, H. Belmili, and F. Krim, "A survey of the most used MPPT methods: conventional and advanced algorithms applied for photovoltaic systems," Renewable and Sustainable Energy Reviews, vol. 45, pp. 637-648, 2015.

[3] R. Sarjila, K. Ravi, J. B. Edward, A. Prasad, and K. S. Kumar, "An AIS based approach for extraction of PV module parameters," in Information Systems Design and Intelligent Applications, Advances in Intelligent Systems and Computing, pp. 405-422, Springer, New Delhi, India, 2016.

[4] X. Yuan, Y. Xiang, and Y. He, "Parameter extraction of solar cell models using mutative-scale parallel chaos optimization algorithm," Solar Energy, vol. 108, pp. 238-251, 2014.

[5] E. Rashedi, H. Nezamabadi-pour, and S. Saryazdi, "GSA: a gravitational search algorithm," Information Sciences, vol. 179, no. 13, pp. 2232-2248, 2009.

[6] R. K. Swain, N. C. Sahu, and P. K. Hota, "Gravitational search algorithm for optimal economic dispatch," Procedia Technology, vol. 6, pp. 411-419, 2012.

[7] http://www.proyectodeenergiarenovable.com/descargas/manuales/guia $\% 20$ para $\% 20$ el $\% 20$ bombeo $\% 20 \mathrm{de} \% 20$ agua $\% 20$ con \%20paneles/material\%20de\%20apoyo/fichas\%20tecnicas/ siemens/shellsolars36_ukv5.pdf.
[8] http://www.gehrlicher.com/fileadmin/content/pdfs/de/ produktarchiv/Shell_ST40.pdf.

[9] http://www.solenerg.com.br/files/SP70.pdf. 


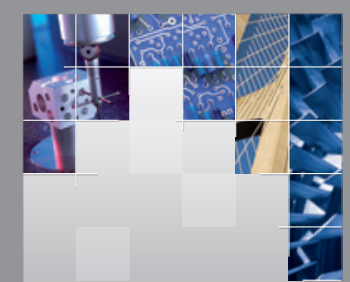

\section{Enfincering}
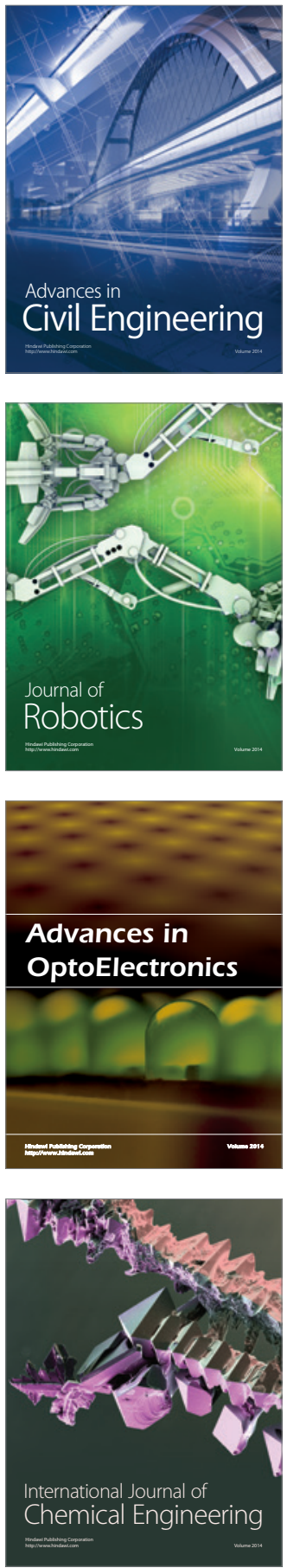

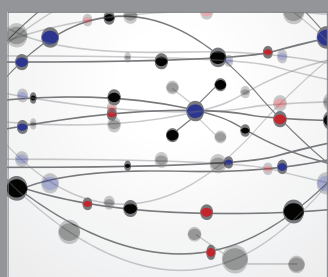

The Scientific World Journal

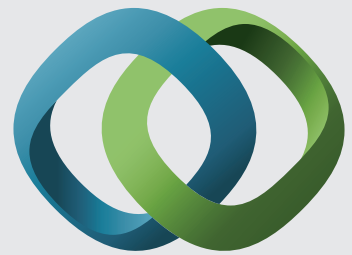

\section{Hindawi}

Submit your manuscripts at

http://www.hindawi.com
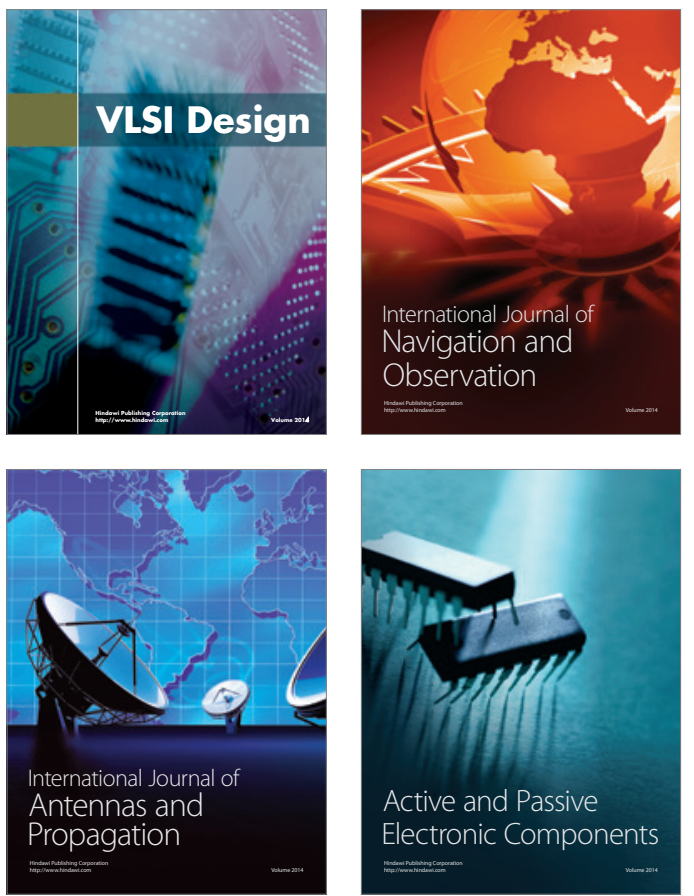
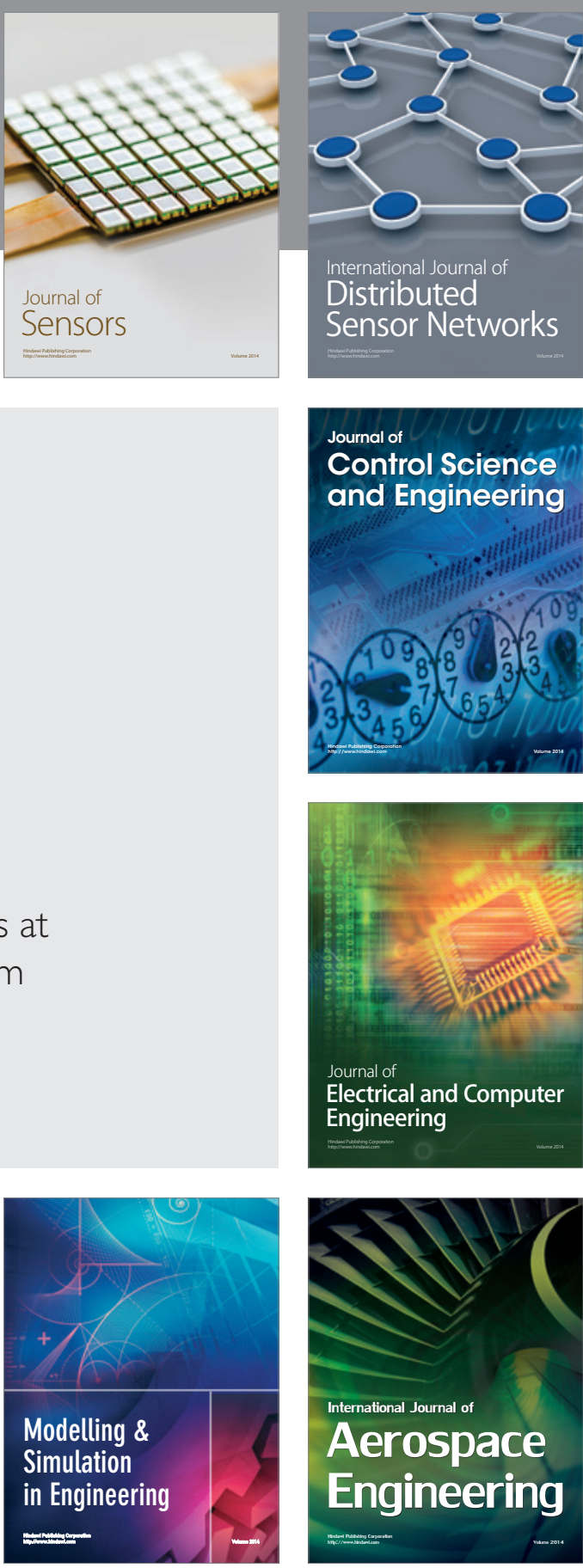

International Journal of

Distributed

Sensor Networks

Journal of

Control Science

and Engineering
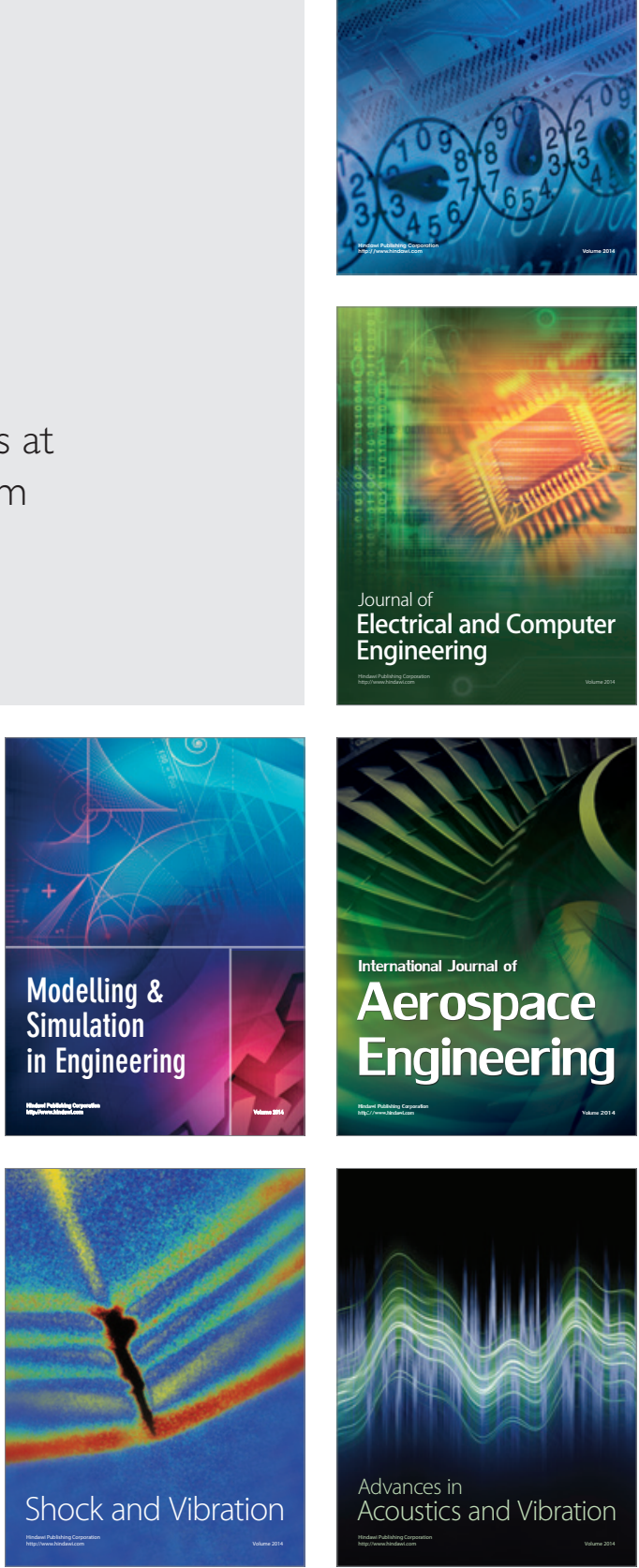